\title{
Safety and Effectiveness of Switching to Abacavir/Lamivudine Plus Rilpivirine for Maintenance Therapy in Virologically Suppressed HIV-1 Patients in Singapore (SEALS)
}

Alvin ZC Lim

$\mathrm{Ng}$ Teng Fong General Hospital, Singapore

Grace SR Hoo ( $\sim$ Grace_sr_hoo@ttsh.com.sg )

National Centre of Infectious Diseases and Tan Tock Seng Hospital, Singapore Junhao Ang

Tan Tock Seng Hospital, Singapore

Christine BC Teng

National University of Singapore, Singapore

Li Wei Ang

National Centre for Infectious Diseases, Singapore

Cheng Chuan Lee

National Centre of Infectious Diseases and Tan Tock Seng Hospital, Singapore and National University of Singapore

\section{Yee Sin Leo}

National Centre of Infectious Diseases and Tan Tock Seng Hospital, Singapore and National University of Singapore

\section{Hwa Lin Law}

Nanyang Technological University, Singapore

\section{Oon-Tek Ng}

Nanyang Technological University, Singapore

\section{Chen Seong Wong}

National Centre of Infectious Diseases and Tan Tock Seng Hospital, Singapore and National University of Singapore

\section{Research}

Keywords: maintenance, switch therapy, virologically suppressed, abacavir, rilpivirine, HIV

Posted Date: November 4th, 2020 
DOI: https://doi.org/10.21203/rs.3.rs-100235/v1

License: (c) (1) This work is licensed under a Creative Commons Attribution 4.0 International License. Read Full License 


\section{Abstract}

\section{Background}

The efficacy and tolerability of an antiretroviral regimen are important considerations for selection of HIV1 infection maintenance therapy. Abacavir/lamivudine plus rilpivirine (ABC/3TC+RPV) has been shown in international studies to be effective and well-tolerated in virologically suppressed patients. This study evaluated the effectiveness and safety of switching to $A B C / 3 T C+R P V$ as maintenance therapy in virologically suppressed HIV-1 infected patients in Singapore.

\section{Methods}

In this retrospective, single-centre study, we included patients who were prescribed ABC/3TC+RPV, had HIV-1 RNA <50 copies/ml immediately pre-switch, and had no documented history of resistance mutations or virologic failure to any of the components. Patients were followed up for $48+12$ weeks. The primary outcome was the proportion of patients who maintained virologic suppression of HIV-1 RNA $<50$ copies $/ \mathrm{ml}$ at the end of follow-up period based on on-treatment analysis. The secondary outcomes were the resistance profiles associated with virologic failure, changes in immunologic and metabolic parameters, and the safety profile of $A B C / 3 T C+R P V$.

Results

A total of 222 patients were included in the study. The primary outcome was achieved in 197 patients [88.8\%, 95\% confidence interval: 83.7\%-92.4\%]. There were 21 patients $(9.5 \%)$ who discontinued treatment for non-virologic reasons. The remaining 4 patients experienced virologic failure, of whom, 3 of these patients had developed emergent antiretroviral resistance and had HIV-1 RNA $>500$ copies $/ \mathrm{ml}$ at the end of the 48+12 weeks follow-up period. The remaining patient experienced sustained low level viremia and subsequently achieved viral suppression without undergoing resistance testing. A total of 49 adverse events were observed in 31 out of 222 patients (14.0\%), which led to 13 patients discontinuing therapy. Neuropsychiatric adverse events were most commonly observed $(57.1 \%)$. A statistically significant increase in CD4 was observed $(p<0.01)$, with a median absolute change of 31 cells/uL (interquartile range: -31.50 to 140.75$)$. No significant changes in lipid profiles were detected.

\section{Conclusion}

$A B C / 3 T C+R P V$ is a safe and effective switch option for maintenance therapy in virologically suppressed HIV-1 patients with in Singapore.

\section{Background}

Modern combination antiretroviral therapy (ART) regimens have generally demonstrated potency and efficacy in achieving virologic suppression. ${ }^{1}$ Owing to the chronic nature of HIV infection, maintenance therapy is required even after initial virologic suppression. ${ }^{1}$ In addition to efficacy, the cost-effectiveness, 
convenience and long-term tolerability of the ART are important considerations in selecting a suitable maintenance therapy. ${ }^{1}$

The current standard for HIV treatment is combination ART, which comprise of two nucleos(t)ide reverse transcriptase inhibitors (NRTI) as backbone, paired with a third agent from another class, including integrase strand transfer inhibitors (INSTI), non-nucleoside reverse transcriptase inhibitors (NNRTI), or protease inhibitors (PI). ${ }^{1}$ Tenofovir and emtricitabine (TDF/FTC) are recommended as a first-line NRTI backbone for their effectiveness, but the combination of abacavir and lamivudine (ABC/3TC) may be used as maintenance therapy for its cost-effectiveness and better safety profile. ${ }^{1-4}$ Compared to tenofovir-based regimens, $\mathrm{ABC} / 3 \mathrm{TC}$ offer the advantage of avoiding potential renal and bone toxicity and is suitable for use in individuals with renal insufficiency and osteoporosis. ${ }^{1-4}$ In Singapore, the price of $A B C / 3 T C$ is roughly half that of TDF and 3TC (as separate components), and one-fifth the cost of a TDF/FTC fixed dose combination tablet. Rilpivirine (RPV) is a second-generation NNRTI approved for use with NRTIs in treatment-naïve HIV-1 infected patients. ${ }^{5-9}$ Its use is recommended to be limited to patients with pre-treatment CD4 counts exceeding $200 \mathrm{cells} / \mathrm{uL}$ and pre-treatment viral loads of less than 100,000 copies/ml. ${ }^{1}$ RPV has been shown to have fewer neuropsychiatric adverse effects (AEs) when compared with efavirenz, a more favourable metabolic profile compared with $\mathrm{PI}$, and better cost-effectiveness due to its relatively lower cost. ${ }^{5-9}$ In Singapore, the cost of RPV is $25 \%$ compared to that of a PI or INSTI.

The SIMRIKI retrospective study has demonstrated the long-term effectiveness and safety of ABC/3TC + RPV as a switch therapy with a follow-up period of up to 48 weeks. ${ }^{10}$ The results of the SIMRIKI study are corroborated by several similar Spanish studies. ${ }^{11-13} \mathrm{~A}$ local study has also shown the efficacy and safety of this regimen in treatment naïve HIV-1 infected adults, ${ }^{14}$ but to our knowledge, there have not been any studies on the effectiveness and safety of $A B C / 3 T C+R P V$ as a switch regimen in Singapore.

The aim of this study was to evaluate the effectiveness and safety of switching to ABC/3TC + RPV as maintenance therapy for virologically suppressed HIV-1 infected patients in Singapore.

\section{Methods}

This study was a retrospective, single-centre evaluation conducted at National Centre for Infectious Diseases (NCID), which provides HIV care for the majority of HIV-infected individuals in Singapore. The study was conducted between June 2014 and September 2018. Approval from Domain Specific Review Board of the National Healthcare Group (Reference Number: 2012/00438-SRF0006) was obtained prior to study commencement.

The inclusion criteria were as follows: i) documented HIV-1 infection, ii) age $\geq 18$ years, iii) use of combination of ABC/3TC (600/300 mg fixed dose combination once daily) plus RPV ( $25 \mathrm{mg}$ once daily) as maintenance therapy between June 2014 and September 2018 inclusive, iv) virologically suppressed (defined as having at least 1 reading of HIV-1 RNA $<50$ copies $/ \mathrm{ml}$ ) immediately before switching to $A B C / 3 T C+R P V$, and $v$ ) no documented history of resistance mutations or virologic failure to $A B C, 3 T C$, 
FTC or RPV. Exclusion criteria were CD4 count $<200$ cells/uL and pregnancy. As adherence could not be determined for patients who either obtained external supply of ART with no pharmacy dispensed records and/or with erratic clinic attendance, patients with proportion of days covered (PDC) for adherence of < 95\% were also excluded. PDC was calculated by the following formula: [Number of days with medication supply in study period / number of days in the study period] $\times 100$, capped at $100 \%$. PDC is a known, validated and stringent measure of patient adherence. ${ }^{15,16}$ The cut-off for PDC was chosen to be $95 \%$ as it is a widely used standard for optimal ART. ${ }^{17}$

Eligible patients were identified from the NCID HIV Clinical Database, a standardised computerised database containing records of demographic information, HIV transmission route, and ART history. Data collected from electronic medical records included AEs attributed to ART, reasons for ART switch, and other laboratory readings which were not available on the Clinical Database. Data were anonymised upon extraction. Intervals for follow-up were determined by individual attending physicians per in-house clinical care guidelines.

The primary outcome measured was the proportion of patients who maintained virologic suppression on $\mathrm{ABC} / 3 \mathrm{TC}+\mathrm{RPV}$ after $48 \pm 12$ weeks of follow-up and had no therapy discontinuation due to non-virologic reasons such as adverse drug reactions. Patients were considered to have maintained virologic suppression if they had no virologic failure. Virologic failure was defined as: i) 2 consecutive HIV-1 RNA readings of $>50$ copies $/ \mathrm{ml}$, ii) any HIV-1 RNA reading of $>50$ copies $/ \mathrm{ml}$ that resulted in discontinuation of $\mathrm{ABC} / 3 \mathrm{TC}+\mathrm{RPV}$, or iii) any HIV-1 RNA reading of $>500 \mathrm{copies} / \mathrm{ml}$. This definition for virological failure is similar to the SIMRIKI study, ${ }^{10}$ but also included any HIV-1 RNA reading of $>500$ copies $/ \mathrm{ml}$ to detect any potential emergent antiretroviral resistance. Patients who had a one-off HIV-1 RNA reading between 51 copies/ml and $<199$ copies/ml that was followed by a return to virologic suppression were considered virologic blips. ${ }^{1}$ For all patients, HIV-1 RNA was measured at least twice throughout the follow-up period.

The secondary outcomes were the resistance profiles associated with virologic failure, changes in immunologic and metabolic parameters, and the AE profile of ABC/3TC + RPV. For the immunologic and metabolic parameters, only patients who had both baseline and follow-up values were analyzed for secondary outcomes.

The $95 \%$ confidence intervals (Cl) were calculated based on the Newcombe-Wilson hybrid score. ${ }^{18} \mathrm{We}$ checked whether the continuous variables were normally distributed using the Kolmogorov-Smirnov test (for $n \geq 50$ ) and Shapiro-Wilk test (for $n<50$ ). We then used the paired samples $t$-test to analyze variables with normal distribution, and the Wilcoxon Signed Rank test to analyze variables with non-normal distribution. All statistical tests were two-sided, and p-values $<0.05$ were considered statistically significant. Statistical analysis was carried out using the IBM SPSS Statistics for Windows, version 24.0 (Armonk, NY: IBM Corp).

\section{Results}


A total of 346 patients were screened. We included 222 patients for analysis. The inclusion process of the study was detailed in Fig. 1. Baseline characteristics of the patients included in the study were displayed in Table 1. 
Table 1

Baseline characteristics of study population

\section{Baseline Characteristic}

Age (years), median (IQR)

$47(35-57)$

Male, $\mathrm{n}(\%)$

$205(92.3)$

Race, $n(\%)$

Chinese

$176(79.3)$

Malay

$32(14.4)$

Indian

$12(5.4)$

Others

$2(0.9)$

\section{HIV Risk Group, n (\%)}

Heterosexual Contact Only

$96(43.2)$

Homosexual Contact Only

$93(41.9)$

Others

$28(12.6)$

Unknown

$5(2.3)$

Previous ART, $\mathbf{n}(\%)$

Backbone Tenofovir/Lamivudine or Tenofovir/Emtricitabine $135(60.8)$

Abacavir/Lamivudine $\quad 60(27.0)$

Zidovudine/Lamivudine

$23(10.3)$

Stavudine/Lamivudine

$4(1.9)$

Third Agent Efavirenz

$94(42.3)$

Rilpivirine

$52(23.4)$

Atazanavir/ritonavir

30 (13.5)

Nevirapine

$20(9.0)$

Raltegravir

$15(6.8)$

Darunavir/ritonavir

5 (2.3)

Dolutegravir

4 (1.8)

Lopinavir/ritonavir

$2(0.9)$

IQR, interquartile range 


\begin{tabular}{|ll|}
\hline Baseline Characteristic & \\
\hline Reasons for switching to ABC/3TC + RPV, $\mathbf{n}(\%)$ & $117(52.7)$ \\
\hline Intolerance & $66(29.7)$ \\
\hline Cost reduction & $52(23.4)$ \\
\hline Simplification of regimen & $5(2.3)$ \\
\hline Drug-drug interaction & $3(1.4)$ \\
\hline Others & $31(14.0)$ \\
\hline Unknown & \\
\hline Comorbidities, $\mathbf{n}$ (\%) & $4(1.8)$ \\
\hline Myocardial infarction & $5(2.3)$ \\
\hline Ischemic heart disease & $7(3.2)$ \\
\hline Other cardiovascular pathologies & $39(17.6)$ \\
\hline Hypertension & $18(8.1)$ \\
\hline Diabetes mellitus & $67(30.2)$ \\
\hline Dyslipidemia & $15(6.8)$ \\
\hline Kidney disease & $7(3.2)$ \\
\hline Hepatitis B & $16(7.2)$ \\
\hline Hepatitis C & $63(28.4)$ \\
\hline No. of patients with 5 or more medications (polypharmacy), $\mathrm{n}(\%)$ & $41(18.5)$ \\
\hline Current smokers, $\mathrm{n}(\%)$ & \\
\hline IQR, interquartile range & \\
\hline
\end{tabular}

The median age was 47 years (interquartile range [IQR]:35-57). Majority of the patients were male (92.3\%). The composition of pre-switch NRTI backbone (in combination with either 3TC or FTC) was as follows: TDF (60.8\%), ABC (27.0\%) zidovudine (10.3\%), and stavudine (1.9\%). The most common preswitch third agents were efavirenz (42.3\%) among the NNRTI, atazanavir/ritonavir (13.5\%) among the PI, and raltegravir (6.8\%) among the INSTI. Fifty-two (23.4\%) patients already had RPV as their third agent prior to switch. The most common pre-switch combination was TDF + 3TC + RPV, which accounted for $45 / 222(20.3 \%)$ of all pre-switch regimens. Intolerance $(52.7 \%)$, cost $(29.7 \%)$, and simplification of regimen $(23.4 \%)$ were the most common reasons cited for switching regimen. Thirty-one patients (14.0\%) had no documented reason for switch. 
The primary outcome was achieved in 197 out of 222 patients [88.8\%, 95\% confidence interval $(\mathrm{Cl})$ : 83.7\%-92.4\%]. Four patients (1.8\%) had virologic failure (Supplementary Table 1), while 21 patients (9.5\%) discontinued treatment for non-virologic reasons before $48 \pm 12$ weeks (Supplementary Table 2). Among those who achieved the primary outcome, 7 patients had viral blips during the $48 \pm 12$ weeks follow-up period.

Of the 4 patients who experienced virologic failure, 3 patients had HIV-1 RNA $>500$ copies $/ \mathrm{ml}$ at the end of the study period and developed emergent antiretroviral resistance. The first patient experienced virologic failure on the 52th week of switching regimen. Resistance testing showed M184MIV, V108VI, E138EK, K238KN mutations. This patient reported no missed doses, but administered ART at irregular timings with inconsistent caloric intake. The second patient failed on the 45th week of ABC/3TC + RPV and had M184I, E138K, H221HY mutations. He estimated missing doses once a week, and having erratic meal consumption. The third patient experienced virologic failure within 17 weeks of switching regimen, with emerging resistance mutations consisting of L74LV, M184I, E138EG, Y181YCF, M230L. This patient claimed full adherence to his ART, including administration with meals. The last patient had 3 consecutive readings of low-level viremia (HIV-1 RNA $>50$ copies/ml but $<200$ copies/ml). This patient later achieved virologic suppression without the need to change regimen after the study period.

Among the 21 patients who discontinued treatment for non-virologic reasons, 13/21 (61.9\%) were due to AEs attributed to ABC/3TC + RPV. The details of these AEs that led to discontinuation are reported in Supplementary Table 2. Of the remaining 8/21 (38.1\%) patients that discontinued treatment for nonvirologic reasons, half were to avoid drug-drug interactions with other concomitant medications, and onequarter were due to personal financial issues. A total of $49 \mathrm{AEs}$ were observed in 31 out of 222 patients (14.0\%) during the follow-up period (Table 2). All the AEs resolved spontaneously or upon therapy discontinuation. The most common type of $A E$ was neuro-psychiatric (i.e. forgetfulness, insomnia, mood changes, vivid dreams), comprising 28/49 (57.1\%) of all AEs reported.

Table 2

Summary of adverse events

\begin{tabular}{|lc|}
\hline Summary of adverse effects & $\mathbf{n}$ \\
\hline Total number of adverse effects & 49 \\
\hline Patients with $\geq 1$ adverse effects & 31 \\
\hline Patients who discontinued therapy due to adverse effects & 13 \\
\hline Types of adverse effects & $\mathbf{n}$ \\
\hline Neuro-psychiatric (i.e. forgetfulness, insomnia, mood changes, vivid dreams) & 28 \\
\hline Digestive (i.e. abdominal pain, stomach-ache) & 11 \\
\hline Dermatological (i.e. rash) & 4 \\
\hline Others (e.g. fatigue, lipodystrophy, gynecomastia) & 6 \\
\hline
\end{tabular}


Data obtained on changes in the selected laboratory values over the study duration are summarized in Table 3. A statistically significant increase in CD4 was observed $(p<0.01)$, with a median absolute change of 31 cells/uL (IQR: -31.50 to +140.75 ). There were no significant changes in fasting blood glucose and $\mathrm{HbA} 1 \mathrm{c}$ after switching regimen, based on the small number of patients analysed (11 patients for fasting blood glucose and 8 patients for $\mathrm{HbA} 1 \mathrm{c}$ ). There was a statistically significant change observed for eGFR $(p<0.01)$, with a median absolute change of $-4.24 \mathrm{ml} / \mathrm{min} / 1.73 \mathrm{~m}^{2}$ (IQR: -14.06 to + 5.27), while no significant change was detected for $\mathrm{eCrCl}(\mathrm{p}=0.463)$, with a median absolute change of $-0.79 \mathrm{ml} / \mathrm{min}$ (IQR: -8.81 to +7.97 ). No significant changes in lipid profiles were detected. A statistically significant decrease of $-6 \mathrm{U} / \mathrm{L}$ (IQR: -11 to 0 ) was seen for ALT. 
Table 3

Laboratory values at baseline and at end of follow-up period

\begin{tabular}{|c|c|c|c|}
\hline Laboratory parameter & & Median (IQR) & $\begin{array}{l}\mathrm{p}- \\
\text { value }\end{array}$ \\
\hline \multirow[t]{4}{*}{ Absolute CD4 Count $(n=38)$} & Baseline (cells/uL) & $\begin{array}{l}323(220 \text { to } \\
519)\end{array}$ & \\
\hline & Follow up (cells/uL) & $\begin{array}{l}397(252 \text { to } \\
603)\end{array}$ & \\
\hline & Follow up Duration (Weeks) & 49 (44 to 52$)$ & \\
\hline & Change (cells/uL) & $\begin{array}{l}31(-32 \text { to }+ \\
141)\end{array}$ & $\begin{array}{l}< \\
0.01^{b}\end{array}$ \\
\hline \multicolumn{4}{|l|}{ Glucose Monitoring } \\
\hline \multirow[t]{4}{*}{ Fasting blood glucose $(n=11)$} & Baseline (mmol/L) & $\begin{array}{l}5.1 \text { ( } 4.9 \text { to } \\
5.7)\end{array}$ & \\
\hline & Follow Up (mmol/L) & $\begin{array}{l}5.2(4.7 \text { to } \\
5.5)\end{array}$ & \\
\hline & Follow up Duration (Weeks) & 50 (46 to 52$)$ & \\
\hline & Change (mmol/L) & $\begin{array}{l}0.3(-0.5 \text { to }+ \\
0.4)\end{array}$ & $0.654^{b}$ \\
\hline \multirow[t]{4}{*}{$\mathrm{HbA1c}(\mathrm{n}=8)$} & Baseline (\%) & $\begin{array}{l}5.75(5.55 \text { to } \\
6.5)\end{array}$ & \\
\hline & Follow Up (\%) & $\begin{array}{l}5.85 \text { (5.5 to } \\
6.78)\end{array}$ & \\
\hline & Follow up Duration (Weeks) & 50 (40 to 58$)$ & \\
\hline & Absolute Change (\%) & $\begin{array}{l}0.05(-0.08 \text { to } \\
+0.2)\end{array}$ & $0.288^{a}$ \\
\hline \multicolumn{4}{|l|}{ Renal } \\
\hline \multirow[t]{4}{*}{ eGFR $(n=139)$} & Baseline $\left(\mathrm{ml} / \mathrm{min} / 1.73 \mathrm{~m}^{2}\right)$ & $\begin{array}{l}90(78 \text { to } \\
104)\end{array}$ & \\
\hline & Follow Up $\left(\mathrm{ml} / \mathrm{min} / 1.73 \mathrm{~m}^{2}\right)$ & 87 (76 to 99) & \\
\hline & Follow up Duration (Weeks) & 49 (40 to 54$)$ & \\
\hline & Change $\left(\mathrm{ml} / \mathrm{min} / 1.73 \mathrm{~m}^{2}\right)$ & $-4(-14$ to 5$)$ & $\begin{array}{l}< \\
0.01^{b}\end{array}$ \\
\hline $\mathrm{eCrCl}(n=139)$ & Baseline (ml/min) & $\begin{array}{l}91(76 \text { to } \\
106)\end{array}$ & \\
\hline
\end{tabular}




\begin{tabular}{|c|c|c|c|}
\hline \multicolumn{2}{|l|}{ Laboratory parameter } & \multirow{2}{*}{$\begin{array}{l}\text { Median (IQR) } \\
90(76 \text { to } \\
106)\end{array}$} & \multirow{2}{*}{$\begin{array}{l}\mathrm{p}- \\
\text { value }\end{array}$} \\
\hline & Follow Up (ml/min) & & \\
\hline & Follow up Duration (Weeks) & 49 (40 to 54$)$ & \\
\hline & Change (ml/min) & $-1(-9$ to +8$)$ & $0.423^{\mathrm{a}}$ \\
\hline \multicolumn{4}{|l|}{ Lipids } \\
\hline \multirow[t]{4}{*}{$\mathrm{TC}(\mathrm{n}=38)$} & Baseline (mmol/L) & $\begin{array}{l}5.1 \text { ( } 4.6 \text { to } \\
6.0)\end{array}$ & \\
\hline & Follow Up (mmol/L) & $\begin{array}{l}5.2(4.4 \text { to } \\
5.8)\end{array}$ & \\
\hline & Follow up Duration (Weeks) & 51 (45 to 54$)$ & \\
\hline & Change (mmol/L) & $\begin{array}{l}0.1(-1.1 \text { to }+ \\
0.8)\end{array}$ & $0.778^{b}$ \\
\hline \multirow[t]{4}{*}{ HDL-C $(n=38)$} & Baseline (mmol/L) & $\begin{array}{l}1.0(0.9 \text { to } \\
1.4)\end{array}$ & \\
\hline & Follow Up (mmol/L) & $\begin{array}{l}1.2(0.9 \text { to } \\
1.3)\end{array}$ & \\
\hline & Follow up Duration (Weeks) & 50 (45 to 54$)$ & \\
\hline & Change (mmol/L) & $\begin{array}{l}0(-0.2 \text { to }+ \\
0.2)\end{array}$ & $0.762^{b}$ \\
\hline \multirow[t]{4}{*}{$d C$ LDL-C $(n=38)$} & Baseline (mmol/L) & $\begin{array}{l}2.9 \text { (2.6 to } \\
3.6)\end{array}$ & \\
\hline & Follow Up (mmol/L) & $\begin{array}{l}2.8(2.4 \text { to } \\
3.5)\end{array}$ & \\
\hline & Follow up Duration (Weeks) & 51 (45 to 54$)$ & \\
\hline & Change (mmol/L) & $\begin{array}{l}-0.1(-0.5 \text { to } \\
+0.5)\end{array}$ & $0.817^{b}$ \\
\hline \multirow[t]{4}{*}{ LDL-C (n = 35) } & Baseline (mmol/L) & $\begin{array}{l}3.1 \text { (2.6 to } \\
3.7)\end{array}$ & \\
\hline & Follow Up (mmol/L) & $\begin{array}{l}3.1 \text { ( } 2.7 \text { to } \\
3.7)\end{array}$ & \\
\hline & Follow up Duration (Weeks) & 51 (45 to 54$)$ & \\
\hline & Change (mmol/L) & $\begin{array}{l}0.1(-0.6 \text { to }+ \\
0.7)\end{array}$ & $0.972^{b}$ \\
\hline
\end{tabular}




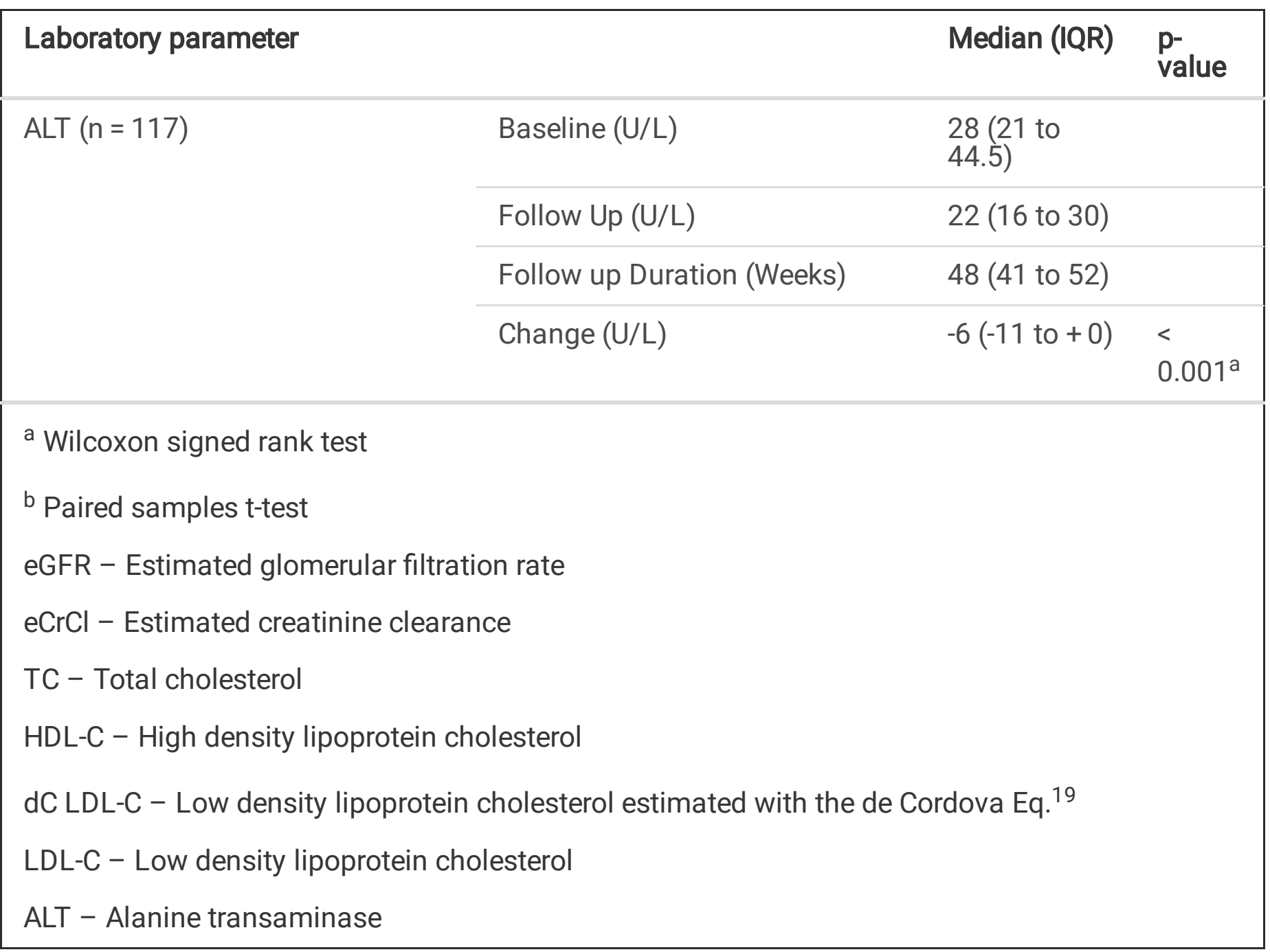

\section{Discussion}

Our results showed that a high proportion of patients (88.8\%) who switched to ABC/3TC + RPV had maintained virologic suppression. In several studies in Spain, $86-88 \%$ of HIV patients maintained virologic suppression and avoided therapy discontinuation at 48 weeks or 12 months. ${ }^{11-13}$ The SIMRIKI study also saw $91.2 \%$ of their study population achieving the same outcome at 48 weeks. ${ }^{10} \mathrm{~A}$ local study found that $96 \%$ of treatment naïve HIV-1 infected patients achieved virologic suppression at the end of 48 weeks of treatment with $\mathrm{ABC} / 3 \mathrm{TC}+\mathrm{RPV}_{1}{ }^{14}$ which was comparable to that of our study in which $98.0 \%$ $(197 / 201)$ of patients who completed follow-up without therapy discontinuation remained virologically suppressed. The findings of our study reinforce existing primary literature that $A B C / 3 T C+R P V$ can achieve effective, sustained virologic suppression. In the minority cases that fail ABC/3TC + RPV, patients still have the option of switching to a salvage regimen which includes a PI or INSTI or both.

AEs were observed amongst $31 / 222$ patients (14.0\%) and resolved either spontaneously or upon discontinuation of the medication. These results were comparable to the favourable results of SIMRIKI study, ${ }^{10}$ as well as the local study on treatment-naïve HIV-infected patients, ${ }^{14}$ which reported only $15.6 \%$ and $13.5 \%$ of patients with observed AEs respectively. The AE profile seen in our study was also very 
similar to the local study which saw mostly neuropsychiatric AEs at a rate of $46.4 \%$ of all observed AEs compared to our study which saw $57.1 \%$ of observed AEs being neuropsychiatric. ${ }^{14}$ These findings further support the well-established safety and tolerability of ABC/3TC + RPV.

Our patients had a significant improvement of absolute CD 4 count at the end of the $48 \pm 12$ weeks followup. The increase in the CD4 count can possibly be attributed to maintained virologic suppression, and was also seen in other switch studies with increases ranging from +48 to +262 cells/uL. ${ }^{11-13}$

We observed a statistically significant decrease in eGFR but not in eCrCl. The median absolute changes in eGFR and eCrCl were deemed to be of little or no clinical relevance, ${ }^{20,21}$ as a median change of $-4 \mathrm{ml} / \mathrm{min} / 1.73 \mathrm{~m}^{2}$ in eGFR or $-1 \mathrm{ml} / \mathrm{min}$ in $\mathrm{eCrCl}$ is unlikely to affect the staging of chronic kidney disease or acute kidney injury. We also observed a statistically significant decrease in ALT, but the magnitude of the change is clinically insignificant, ${ }^{22}$ as the median change of $-6 \mathrm{U} / \mathrm{L}$ is insufficient to warrant any clinical action. Significant changes in eCrCl, eGFR and ALTs were rarely noted in other studies on $A B C / 3 T C+R P V$, and it is likely that the regimen has no significant effect on these laboratory parameters. ${ }^{11-14}$

While no statistically significant changes were detected for lipids, fasting blood glucose and $\mathrm{HbA1c}$, the results warrant careful interpretation due to the small number of patients with both baseline and followup values. Remarkably, the SIMRIKI study and the studies by Curran et al and Palacios et al all noted significant decreases in total cholesterol and LDL-C, as well as increases in HDL-C. ${ }^{10-12}$ However, the local study by $\mathrm{Ho}$ et al did not lend evidence to any significant effect of the regimen on lipids, ${ }^{14}$ and there are no studies so far that we know of that have documented significant changes in fasting blood glucose and $\mathrm{HbA} 1 \mathrm{c}$.

Our study has several limitations. The absence of a control group prevented us from comparing the effectiveness and safety in patients who would have continued with the prior regimen. As we excluded patients who were $<95 \%$ adherent by PDC, our findings may not be generalizable to patients with suboptimal adherence or who are compliant to ART despite irregular clinic attendance or who purchase external supplies of ART. In practice, it will be crucial to take into account the relatively low genetic barrier to resistance and the caloric requirements of RPV when selecting this regimen. The frequency of adverse events may also have been under-reported, as only adverse events that were reported and explicitly attributed to the regimen in the patients' clinical documentation were included in the study.

\section{Conclusion}

In conclusion, this study shows that $A B C / 3 T C+R P V$ is an effective and safe switch option for maintenance therapy in virologically suppressed HIV-1 patients in Singapore.

\section{Declarations}




\section{Ethics approval and consent to participate:}

Ethics approval for use of the clinical data was obtained from the Singapore National Healthcare Group Domain Specific Review Board (Reference Number: 2012/00438-SRF0006).

\section{Consent for publication:}

Not applicable

\section{Availability of data and materials:}

The dataset generated and/or analysed during the current study are not publicly available due to the Personal Data Protection Act in Singapore and the sensitivity of the diagnosis, but reversibly anonymised dataset is available from the corresponding author on reasonable request.

\section{Competing interests:}

The authors declare that they have no competing interests.

\section{Funding:}

None to declare.

\section{Authors' contributions:}

LAZ and AJH collected the data. LAZ performed the analysis. LAZ and HG wrote the manuscript. All authors read and approved the final manuscript.

\section{Acknowledgements:}

We thank the patients and staff in the NCID Clinical HIV Programme who made this possible.

\section{References}

1. Panel on Antiretroviral Guidelines for Adults and Adolescents. Guidelines for the Use of Antiretroviral Agents in Adults and Adolescents with HIV. Department of Health and Human Services. Available at http://www.aidsinfo.nih.gov/ContentFiles/AdultandAdolescentGL.pdf. [Accessed 21 May 2020]

2. Swartz J, Vandekerckhove L, Ammerloon $\mathrm{H}$, et al. Efficacy of tenofovir and efavirenz in combination with lamivudine or emtricitabine in antiretroviral-naive patients in Europe. Journal of Antimicrobial Chemotherapy. 2015;70(6):1850-1857. doi:10.1093/jac/dkv033

3. Colombo G. Cost-effectiveness analysis of initial HIV treatment under Italian guidelines. ClinicoEconomics and Outcomes Research. 2011:197. doi:10.2147/ceor.s24130

4. Eccleston K, Bambumba A, Babu C, et al. Efficacy and safety of tenofovir/emtricitabine compared to abacavir/lamivudine in HIV-1 infected patients in clinical setting. The TEAL study. Journal of the 
International AIDS Society. 2008;11(Suppl 1). doi:10.1186/1758-2652-11-s1-p79

5. Molina J, Cahn P, Grinsztejn B, et al. Rilpivirine versus efavirenz with tenofovir and emtricitabine in treatment-naive adults infected with HIV-1 (ECHO): a phase 3 randomised double-blind activecontrolled trial. The Lancet. 2011;378(9787):238-246. doi:10.1016/s0140-6736(11)60936-7

6. Cohen C, Andrade-Villanueva J, Clotet B, et al. Rilpivirine versus efavirenz with two background nucleoside or nucleotide reverse transcriptase inhibitors in treatment-naive adults infected with HIV-1 (THRIVE): a phase 3, randomised, non-inferiority trial. The Lancet. 2011;378(9787):229-237. doi:10.1016/s0140-6736(11)60983-5

7. Molina J, Clumeck N, Orkin C, et al. Week 96 analysis of rilpivirine or efavirenz in HIV-1-infected patients with baseline viral load $\leq 100000$ copies $/ \mathrm{mL}$ in the pooled ECHO and THRIVE phase 3 , randomized, double-blind trials. HIV Med. 2013;15(1):57-62. doi:10.1111/hiv.12071

8. Gazaignes S, Resche-Rigon M, Gatey C, et al. Efficacy and safety of a switch to rilpivirine-based regimens in treatment-experienced HIV-1-infected patients: a cohort study. Antivir Ther (Lond). 2015;21(4):329-336. doi:10.3851/imp3010

9. Luis Casado J, Bañón S. Recent Advances in Rilpivirine: New Data and Promising Treatment Option. AIDS Rev. 2014;16(3):172-18

10. Troya J, Ryan P, Ribera E, et al. Abacavir/Lamivudine plus Rilpivirine Is an Effective and Safe Strategy for HIV-1 Suppressed Patients: 48 Week Results of the SIMRIKI Retrospective Study. PLoS ONE. 2016;11(10):e0164455. doi:10.1371/journal.pone.0164455

11. Palacios R, Pérez-Hernández I, Martínez M, et al. Efficacy and safety of switching to abacavir/lamivudine (ABC/3TC) plus rilpivirine (RPV) in virologically suppressed HIV-infected patients on HAART. European Journal of Clinical Microbiology \& Infectious Diseases. 2016;35(5):815-819. doi:10.1007/s10096-016-2602-3

12. Curran A, Rojas J, Cabello A, et al. Effectiveness and safety of an abacavir/lamivudine+rilpivirine regimen for the treatment of HIV-1 infection in naive patients. Journal of Antimicrobial Chemotherapy. 2016;71(12):3510-3514. doi:10.1093/jac/dkw347

13. Galizzi N, Galli L, Poli A, et al. Long-term efficacy and safety of rilpivirine plus abacavir and lamivudine in HIV-1 infected patients with undetectable viral load. PLoS One. 2018;13(2). doi:10.1371/journal.pone.0191300.

14. Ho S,Wong JG, Ng OT, et al. AIDS Res Ther. 2020 May 21;17(1):23. doi: 10.1186/s12981-020-002725.PMID: 32438914

15. Bezabhe WM, Chalmers L, Bereznicki LR, Peterson GM. Adherence to Antiretroviral Therapy and Virologic Failure. Medicine. 2016;95(15). doi:10.1097/md.0000000000003361

16. Karve S, Cleves MA, Helm M, et al. Prospective Validation of Eight Different Adherence Measures for Use with Administrative Claims Data among Patients with Schizophrenia. Value in Health. 2009;12(6):989-995. doi:10.1111/j.1524-4733.2009.00543.x

17. Lima VD, Harrigan R, Murray M, et al. Differential impact of adherence on long-term treatment response among naive HIV-infected individuals. AIDS. 2008;22(17):2371-2380. 
doi:10.1097/qad.0b013e328315cdd3

18. Newcombe RG. Two-sided confidence intervals for the single proportion: comparison of seven methods. Stat Med. 1998;17(8):857-872. doi:10.1002/(sici)1097-0258(19980430)17:8<857::aid$\operatorname{sim} 777>3.0 . c 0 ; 2-e$

19. Cordova CMMD, Cordova MMD. A new accurate, simple formula for LDL-cholesterol estimation based on directly measured blood lipids from a large cohort. Annals of Clinical Biochemistry. 2012;50(1):13-19. doi:10.1258/acb.2012.011259.

20. KDIGO 2012 Clinical Practice Guideline for the Evaluation and Management of Chronic Kidney Disease. https://kdigo.org/wp-content/uploads/2017/02/KDIGO_2012_CKD_GL.pdf. Published January 2013.

21. KDIGO Clinical Practice Guideline for Acute Kidney Injury. https://kdigo.org/wpcontent/uploads/2016/10/KDIGO-2012-AKI-Guideline-English.pdf. Published March 2012.

22. Giannini EG. Liver enzyme alteration: a guide for clinicians. Canadian Medical Association Journal. 2005;172(3):367-379. doi:10.1503/cmaj.1040752

\section{Figures}




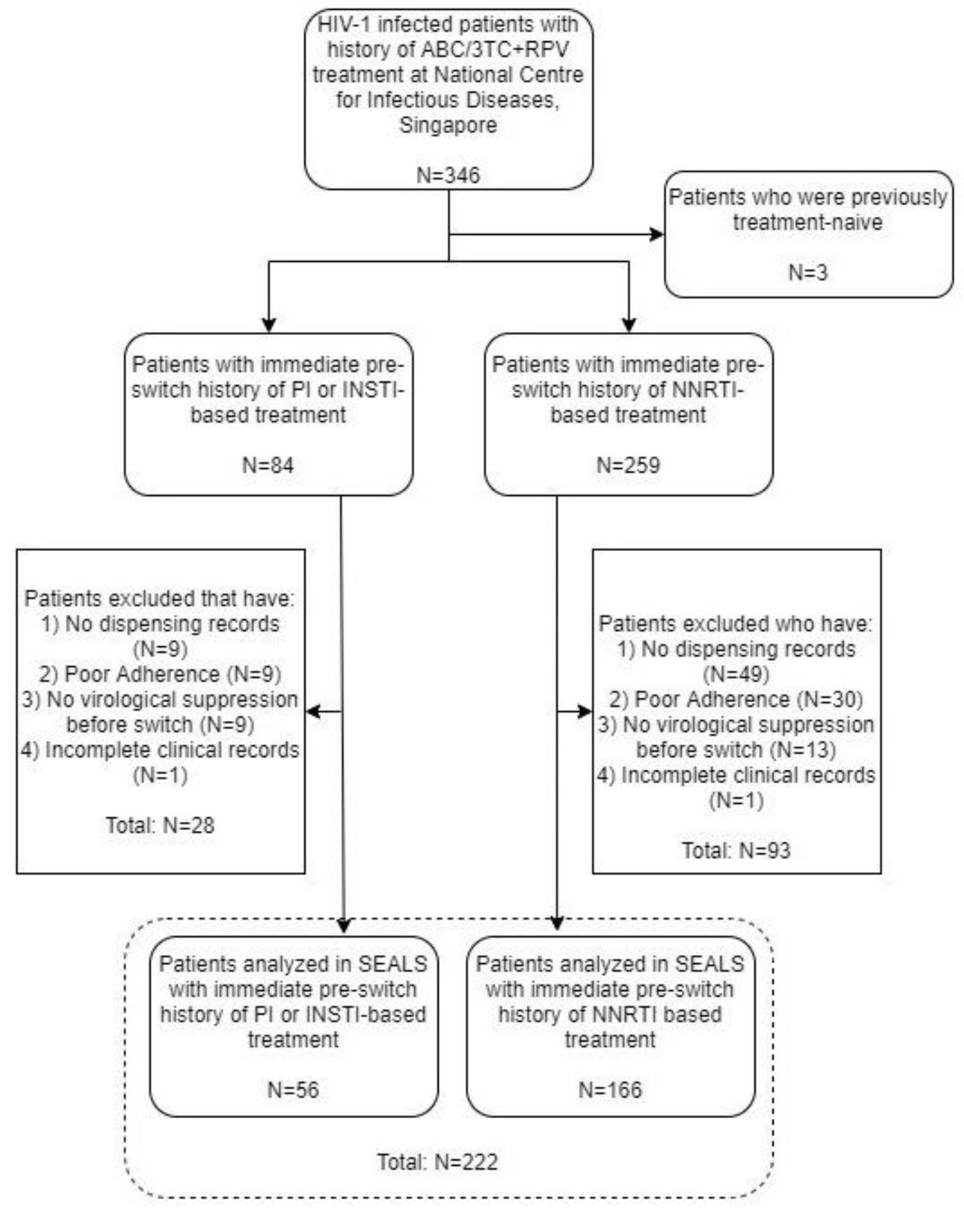

Figure 1

Patient Inclusion Flowchart

\section{Supplementary Files}

This is a list of supplementary files associated with this preprint. Click to download.

- SupplementaryTables.docx 